\title{
Canadian data provide window on statin use
}

$\mathrm{C}$

losing a treatment gap in statin use could prevent an estimated 19500 cardiovascular events each year in Canada, concludes a study published by Statistics Canada based on data from some 3500 Canadians in 2007-2011. But experts disagree over whether that conclusion is robust.

Dr. James Wright, director of British Columbia's Therapeutics Initiative, says, "From my perspective, it is flawed. It is based on a lot of assumptions that I don't accept." Wright was coauthor of a systematic review of statins published in $B M J$ in 2013 that found no overall benefit of preventive statin treatment in lower-risk groups.

However, Dr. Robert Hegele says the study's "overall message is correct." Hegele, director of the Blackburn Cardiovascular Genetics Lab in London, Ontario, says this study confirms others that "have shown underuse in high-risk patients and overuse in lowrisk ones." He says one of its strengths is the use of real patient data.

The data came from two cycles of Statistics Canada's Canadian Health Measures Survey, in which Canadian adults provided full biometric data and tests, including a fasting blood sample, as well as up to 15 current medications. "This is a really rich data source," says principal author Deirdre Hennessy, a research analyst with Statistics Canada's Health Analysis Division. "It collects information that no data source has collected for 25 years. Our driving force was to look at cardiovascular disease [CVD] risk in the Canadian population, evaluate the use of statins and identify treatment gaps."

Using the Canadian Cardiovascular Society's (CCS) 2012 guidelines, participants were classified as high, intermediate or low risk for CVD. Their current statin use was then compared with their risk. The study found that 1 in 10 Canadian adults was taking statins, but this fell far short of the 1 in 4 who would be recommended for treatment under the guidelines.

According to Hegele, the goal is an appropriate match between treatment and risk groups. "One of the things this study shows is that use in the low-risk

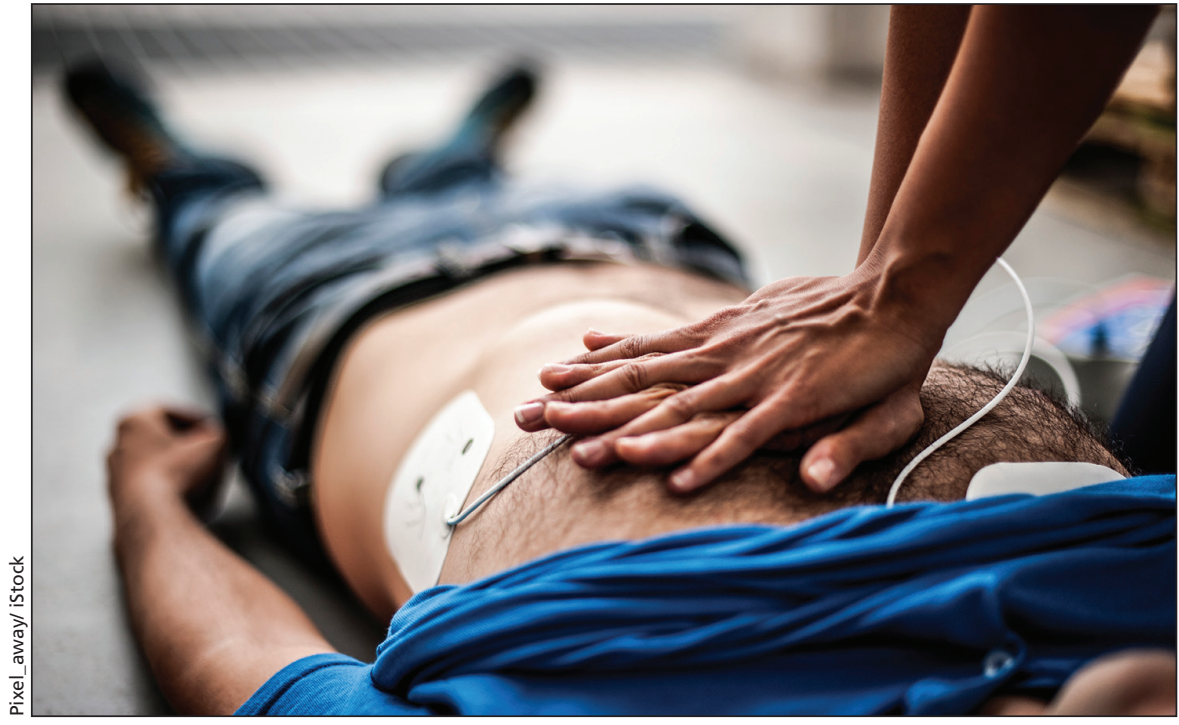

A Statistics Canada study found that 1 in 10 Canadian adults was taking statins, but guidelines recommend 1 in 4 .

group is really low. That's an advance." However, there was underuse in the high-risk group, which Hegele says was not a surprise.

Underuse may be due, in part, to the change in risk definitions over the years. Under previous CCS guidelines, issued in 2009, there were fewer highrisk adults - $13.7 \%$ - whereas under the 2012 guidelines, $20 \%$ of adult Canadians are considered high-risk. The 2012 guidelines added several categories of patients - including those with renal impairment and high-risk hypertension - based on recent randomized controlled trials showing a benefit of statins, says Hegele.

Hennessy acknowledges that the study evaluates statin use based on guidelines that came out after the data were collected. She says the study was not about appropriate prescribing during the study period, but rather about the implications for population health of failing to prevent cardiovascular events.

But Wright is concerned that the study considered only the benefits of statins and not any of the harms. Hennessy acknowledged this limitation: "We wanted to see where we were going in terms of treatment patterns. There are definitely side effects of statins, but it was not part of our thinking."

Wright further argued that "none of these potential benefits are real," calling the study a "thought experiment." He says the study assumes patients take their prescribed medication regularly, despite evidence that more than $50 \%$ stop statins within the first year. Hennessy responded, "We're pretty up front that was an assumption. This was a theoretical comparison of the treatment patterns to the guidelines," and drug adherence was not considered.

Wright also expressed concern that the study extrapolated reduction in CVD events to 10 years, but this was based on randomized trials of shorter duration. Hennessy acknowledged that this is a "good point." She says the trials had various follow-up times, and the benefit was applied to a 10-year algorithm used by CCS, assuming a constant risk reduction. She argued that "evidence bears that out. However, we noted this limitation and say the benefit could very well be an overestimate."

Hennessy hopes the study will contribute to multipronged public awareness campaigns for appropriate prescribing, similar to the kind that led to better hypertension treatment in the 1990s.

Hegele is also optimistic that prescribing statins is becoming more appropriate. "We still have a little ways to go, but at least we have the conversation taking place." - Carolyn Brown, Ottawa, Ont.

CMAJ 2016. DOI:10.1503/cmaj.109-5234 